Journal of Animal and Veterinary Advances 9 (23): 2932-2939, 2010

ISSN: $1680-5593$

(C) Medwell Journals, 2010

\title{
Development of a Novel Recombinant Heamagglutinin-Neuramindase Elisa (rHN-ELISA) for Evaluation of Humoral Immunity in Chicken Vaccinated Against Newcastle Disease Virus (NDV)
}

\author{
${ }^{1}$ Ho-Jin Moon, ${ }^{1}$ Jung-Eun Park, ${ }^{1}$ Hyeon Yoon, ${ }^{1}$ Deu John M. Cruz, \\ ${ }^{1,2}$ Chul-Joong Kim and ${ }^{1,2}$ Hyun-Jin Shin \\ ${ }^{1}$ Laboratory of Infectious Diseases, College of Veterinary Medicine, \\ Chungnam National University, 220 Gungdong, Yuseong, Daejeon, Republic of Korea \\ ${ }^{2}$ Research Institute of Veterinary Medicine, Chungnam National University, \\ 220 Gungdong, Yuseong, Daejeon, Republic of Korea
}

\begin{abstract}
Best known method to prevent recurrent out breaks of Newcastle Disease (ND) is by vaccination with specific viral antigens along with better managemental practices. Even after many viral strains utilized for vaccine development, sporadic incidence of ND outbreaks are reported every year. In the present study, an attempt was made to develop a modified diagnostic tool i.e., a recombinant ELISA (rELISA) using prokaryotic expressed recombinant NDV HN (Hemagglutinin-Neuraminidase) protein i.e., the recombinant ND viral protein was cloned and expressed in E. coli after confirmation of the expression; purified protein was used as the coating antigen for rHN-ELISA to study the utility of the presently commercially available vaccines and to compare the present diagnostic method with other alternative detection methods such as ELISA and HI which justified its potential use as a novel diagnostic assay for NDV vaccines. Therefore, an attempt was made to utilise the $\mathrm{HN}$ glycoproteins which are fundamentally involved in eliciting immune response against NDV, so that evaluation of antibodies against $\mathrm{HN}$ proteins would provide further specific assessment of antibody titres when compared to available diagnostic methods which target to detect antibodies against whole virus. Such novel methods are expected in turn in development of more specific vaccines. Though, rHN-ELISA was inconclusive in its results to substantiate by SN (Serum Neutralizing) test for clearness of neutralizing antibody detection, it may envisage a novel approach towards countering ND outbreaks by supporting its diagnosis and prevention.
\end{abstract}

Key words: Newcastle disease virus, Hemagglutinin neuraminidase, rELISA, comparison, antibody, assessment

\section{INTRODUCTION}

Newcastle Disease Virus (NDV), the only member of the genus Avulavirus belongs to the family Paramyxoviridae (Makkay et al., 1999; Han et al., 2008). It is a frequent pathogen of various avian species, causing severe economic losses in terms of mortality and morbidity in intensive poultry farming units worldwide (Huang et al., 2004). Inevitably, prophylaxis through vaccination is the best known method to control this virus, along with good poultry management practices (Perozo et al., 2008).

Current vaccination programs against NDV include use of lentogenic live-viruses (B1, F and La Sota strains) and attenuated mesogenic viruses $\left(K, R_{2} B\right.$ strains) as vaccines with minimal side effects in fowls (Chimeno et al., 2008). Various routes of vaccine administration such as intra-nasal, per-oral, intraconjunctival, sub-cutaneous and delivery aerosol routes have been evaluated with variable results (Ahmad-Raus et al., 2009). Faulty vaccines and vaccine administration, unscientific poultry breeding practices and incompetent diagnostic tools may have lead to vaccine inefficacy in some poultry farms. Therefore, there is a need to develop a reliable diagnostic tool for monitoring vaccine efficacy. Hence, the rHN-ELISA may be used as an assay to validate the competence of vaccines.

At present, Enzyme-Linked Immunosorbent Assay (ELISA) and Hemagglutination Inhibition (HI) are the commonly used methods for detecting and evaluating the efficacy of vaccine against NDV infection (Kho et al., 2000; Panda et al., 2004). Even after substantial research, developing effective vaccines against NDV has not yet been accomplished. Therefore, development of an

Corresponding Author: Hyun-Jin Shin, Laboratory of Infectious Diseases, College of Veterinary Medicine, Chungnam National University, Gungdong, 220 Yuseong, 305-764 Deajeon, Republic of Korea 
effective NDV vaccine as well as easy and effective diagnostic methods are the primary concerns of scientists involved in this research worldwide. The single negativestrand RNA genome of NDV contains six genes encoding six major structural proteins: HemagglutininNeuraminidase ( $\mathrm{HN}$ ), Fusion protein (F), Nucleoprotein (NP), Matrix protein (M), RNA-dependent RNA polymerase (L) and Phosphoprotein (P) (Laliberte et al., 2007; Kim et al., 2001). Among these, $\mathrm{HN}$ is a multifunctional protein.

It possesses both the receptor recognition and attachment to the receptor on cell surface and neuraminidase activities associated with elution of the virus from the cell surface (Morrison, 2003). HN recognizes sialic acid-containing receptors on target cell surfaces; it promotes the fusion activity, neuraminidase acts by removing the sialic acid from progeny virus particles to prevent self-agglutination of progeny virions (Lamb and Parks, 2007; Mayo, 2002). HN proteins are also known to induce neutralizing antibody production (Orvell et al., 1997).

Therefore, the $\mathrm{HN}$ protein plays an important role in virus infectivity. Humoral immunity produced mainly by $\mathrm{HN}$ protein is usually evaluated using $\mathrm{HI}$ and ELISA methods (Tabidi et al., 2004).

Therefore, the $\mathrm{HN}$ protein must be important in evaluating efficacy of the vaccines. In this study, we expressed a synthetic $\mathrm{HN}$ protein in $E$. coli $i$ and used it as a coating antigen for ELISA (rHN-ELISA). This rHNELISA was used to evaluate vaccine efficiency and detection of NDV infection.

\section{MATERIALS AND METHODS}

HN gene synthesis: The design for the oligonucleotides used for $\mathrm{HN}$ gene amplification was based from the sequence of NDV La Sota strain (NCBI genbank; gi: 3386504). A region coding for a 151 amino acid polyprotein that includes an important antigenic site, specifically the 234-NRKSCS-239 was previously identified to be highly conserved among paramyxoviruses. To amplify this region, a total of 12 primers were designed. The detailed primer information is shown in Table 1. The primers are interconnected by 9 complementary bases on either the $5^{\prime}$ or $3^{\prime}$ end as shown in Fig. 1. The primer whose sequence represents the $5^{\prime}$ terminal of the $\mathrm{HN}$ fragment was flanked with a BamH I site at the 5' end while the primer whose sequence represents the $3^{\prime}$ terminal was flanked with a Hind III, Kpn I and Xho I site and the stop codon TAA. Moreover, the primers were modified for optimal codon usage to increase the expression ratio in $E$. coli.

Cloning: Assembly and amplification of the modified NDV HN protein gene was performed as follows: the first PCR mixture contained all 12 primers ( 10 pmole each), dNTPs $(0.4 \mathrm{mM}), 1 \times$ Pryobest buffer and Pyrobest DNA polymerase (TaKaRa Biotechnology Co. Ltd., Japan) in a $30 \mu \mathrm{L}$ total reaction volume. The 1 st PCR was carried out with 30 cycles of $95^{\circ} \mathrm{C}$ for $30 \mathrm{sec}, 45^{\circ} \mathrm{C}$ for $30 \mathrm{sec}$ and $72^{\circ} \mathrm{C}$ for $30 \mathrm{sec}$. The initial amplicon was purified using Supec-II kit (Takara) and then used as template for second PCR. This PCR was carried out in a $50 \mu \mathrm{L}$ volume by mixing the cDNA above with $2.5 \mu \mathrm{L}$ of each 10 pM sense primer and antisense primer, $1 \mathrm{mM}$ each of dNTPs, $5 \mu \mathrm{L}$ of $10 \times$ PCR buffer $\left(100 \mathrm{mM}\right.$ Tris- $\mathrm{HCl}, 1.5 \mathrm{mM} \mathrm{MgCl}_{2}, 50 \mathrm{mM} \mathrm{KCl}$, $\mathrm{pH}$ 8.3) and 2.5 U EX Taq DNA polymerase (TaKaRa Biotechnology Co. Ltd., Japan).

The PCR reaction was as follows: pre-denaturing temperature of $95^{\circ} \mathrm{C}$ for $5 \mathrm{~min}, 30$ cycles of $95^{\circ} \mathrm{C}$ for $40 \mathrm{sec}$, $52^{\circ} \mathrm{C}$ for $40 \mathrm{sec}, 72^{\circ} \mathrm{C}$ for $40 \mathrm{sec}$ and additional extension $72^{\circ} \mathrm{C}$ for $7 \mathrm{~min}$.

After the final PCR product was analyzed by agarose gel electrophoresis and visualized by staining with ethidium bromide, the fully synthesized $\mathrm{HN}$ gene fragment was cloned in pGEM-T easy vector (Promega, Madison, USA). The plasmids were transformed into $E$. coli $\mathrm{DH} 5 \alpha$ using standard molecular technique. After transformation,

Table 1: The complementary primers for overlapping PCR

\begin{tabular}{lll}
\hline Primers & Sequences & Remarks \\
\hline Sense 1 & 5' CCGGATCCAATTTTATCCCAGCGCCTACTACAGGTTCAGGTTGTACT 3' & BamH I \\
Sense 2 & 5' CATTACTGTTACACCCATAATGTAATTTGTCTGGTTGTCGTGATCAT 3' & \\
Sense 3 & 5' GTGCTCCGTACATCTGCAACAGGGCGTGTATCTTTCTACTCTGCGT 3' & \\
Sense 4 & 5' AAGTCTTGCAGTGTGAGTGCAACTCCACTGGGTTGTGATATGCTGTGT 3' & \\
Sense 5 & 5' TATAACTCAGCTGTCCCTACGCGTATGGTACATGGGCGTTTAGGGTTC 3' \\
Sense 6 & 5' GTCACAACATTATTCGGGGACTGGGTGGCCAACTACCCAGGTGTAGGG 3' \\
Antisense 1 & 5' ACAGTAATGGGTAGCACTCATGTCAAATGATGGAATACGAGTACAACC 3' \\
Antisense 2 & 5' ACGGAGCACACCAAGTGCTAAATACTGATATGAATGTGAATGATCACG 3' \\
Antisense 3 & 5' GCAAGACTTACGATTTTGGGTGTCGTCCAGGTTGATTGAACGCAGAGT 3' \\
Antisense 4 & 5' TGAGTTATAATCTTCTTCCTCTGTCTCCGTGACTTTTGAACACAGCAT 3', & \\
Antisense 5 & 5' TGTTGTGACATCTAAGTCCTTTCATGGTACTGGCCGTCGAACCCTAA 3' & \\
Antisense 6 & 5' CCAAGCTTCCTCGAGAGGTACCTTATTAACGGCTGTCAATAAAAGAACCACCCCCT & \\
& ACACC 3' & Stop codon, Hind III, \\
\hline
\end{tabular}




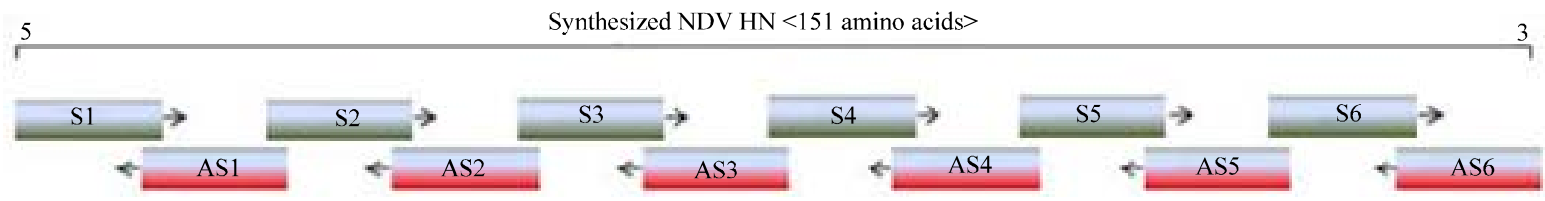

Fig. 1: The illustration of synthesizing NDV-HN gene fragment by overlapping PCR. The Sense (S) primer and Antisense (AS) primer were interconnected on their 5' and 3' ends by 9 complementary bases. A BamHI site was inserted on the 5' end of the 1st upstream oligonucleotide (NDV sense 1) while a HindIII, XhoI, KpnI site and the stop codon (TAA) were inserted on the downstream antisense oligonucleotide (NDV antisense 6). It was performed by Pyrobest polymerase to complete the modified NDV-HN gene fragment which induces high expression in E. coli

BamHI and XhoI restriction enzyme sites were used to select a correct clone and the selected construct was inquired for commercialized sequencing (Solgent, Korea). At least, 3 independent plasmid clones were analyzed, confirmed and sequenced.

NDV HN expression: NDV HN gene fragment produced by BamHI/XhoI double digestion was subcloned into pET43-1a bacterial expression vector (Novagen, USA) and designated as pET43-1a:HN. To express the recombinant $\mathrm{HN}$ protein, pET43-1 a:HN was transformed into $E$. coli, DE3 strain and cultured in a strong selection medium $(100 \mathrm{~mL} 2 \times$ Luria-bertani broth medium containing $100 \mu \mathrm{g} \mathrm{mL}^{-1}$ ampicillin and $34 \mu \mathrm{g} \mathrm{mL}^{-1}$ chloramphenicol) at $30^{\circ} \mathrm{C}$. Induction was done by adding $2 \mathrm{mM}$ Isopropylthio- $\beta$-D-Galactoside (IPTG).

After IPTG induction, the cells were harvested by centrifugation and suspended in lysis buffer $(50 \mathrm{mM}$ $\mathrm{NaH}_{2} \mathrm{PO}_{4}, 300 \mathrm{mM} \mathrm{NaCl}, 10 \mathrm{mM}$ imidazole, $\mathrm{pH} 8.0$ ) with $2 \mathrm{mM}$ PMSF (Phenylmethylsulfonyl Fluoride) and then sonicated 6 times at $25 \%$ amplitude for 5 min each. After sonication, the cell debris was separated by centrifugation at $12,000 \mathrm{rpm}$ for $15 \mathrm{~min}$. The expression was monitored every $0,2,4$ and $24 \mathrm{~h}$ by SDS-PAGE and Western blotting.

NUS-S-His-NDV HN fusion protein purification: To purify expressed NDV $\mathrm{HN}$ protein which is expressed as a fused form with NUS-S and Histidine tag proteins, the Ni-NTA agarose beads were used (Qiagen, USA) following manufacturer's instruction.

The cell lysates were transferred to a new tube and mixed with $500 \mu \mathrm{L}$ Ni-NTA agarose beads for $3 \mathrm{~h}$ at room temperature. The protein captured agarose beads were transferred into a column and washed with $5 \mathrm{~mL}$ wash buffer $\left(50 \mathrm{mMNaH}_{2} \mathrm{PO}_{4}, 300 \mathrm{mMNaCl}, 10 \mathrm{mM}\right.$ imidazole, $\mathrm{pH}$ 8.0). Finally, the recombinant protein was eluted and fractionated using $2.5 \mathrm{~mL}$ elution buffer $\left(50 \mathrm{mM} \mathrm{NaH}_{2} \mathrm{PO}_{4}\right.$, $300 \mathrm{mM} \mathrm{NaCl}, 250 \mathrm{mM}$ imidazole).
Haemagglutination Inhibition (HI) assay: Before $\mathrm{HI}$ test, the viral titer of NDV La Sota was determined by Hemagglutination Assay (HA), the reconstituted to $4 \mathrm{HA}$ Units (4 HAU). Serum was collected from local farms in South Korea and tested for anti-NDV antibodies by $\mathrm{HI}$ assay. Briefly, $25 \mu \mathrm{L}$ of PBS was dispensed onto each well of a plastic round bottomed microtitre plate (Nunc, Denmark) and $25 \mu \mathrm{L}$ of two-fold diluted serum was mixed with the PBS in each well. The reconstituted virus was added at $25 \mu \mathrm{L}$ volume to each well and left for a minimum of $30 \mathrm{~min}$ at room temperature. After incubation, $25 \mu \mathrm{L}$ of $1 \%(\mathrm{v} / \mathrm{v})$ chicken $\mathrm{RBC}$ was added into each well and then gently mixed. The plate was further incubated at $37^{\circ} \mathrm{C}$ for $40 \mathrm{~min}$ and titres were recorded.

Recombinant HN-ELISA (rELISA): Purified NDV HN protein (100 ng) in $0.1 \mathrm{M}$ sodium bicarbonate buffer (pH 9.6) was immobilized onto 96 well microtiter plate (Nunc, Denmark) for $12 \mathrm{~h}$ at $4^{\circ} \mathrm{C}$. After washing 3 times with PBS containing $0.05 \%$ Tween 20 (PBS-T), the sensitized wells was blocked with $400 \mu \mathrm{L} 10 \%$ skim milk in PBS for $3 \mathrm{~h}$ at room temperature. After blocking, the wells were washed with PBS-T 3 times. About $100 \mu \mathrm{L}$ of diluted negative serum or field serum (1:200 in $2 \%$ skim milk in PBS) was added to corresponding wells and incubated for $2 \mathrm{~h}$ at room temperature. The serum samples were removed and washed again for 3 times with PBS-T. To visualize the reaction, $100 \mu \mathrm{L}$ of horseradish peroxidase-conjugated mouse anti-chicken IgG (Sigma-Aldrich) in PBS with $2 \%$ skim milk (1:1000) was added for $2 \mathrm{~h}$ at $37^{\circ} \mathrm{C}$ then washed 5 times with PBS-T. After the final washing, $100 \mu \mathrm{L}$ of $0.4 \mathrm{mg} \mathrm{mL} \mathrm{m}^{-1} \mathrm{O}-\mathrm{Ph}$ nylenediamine (OPD) (Calbiochem, USA) and $\mathrm{H}_{2} \mathrm{O}_{2}$ were added and the reaction was allowed to proceed for 15-20 $\mathrm{min}$ at room temperature before being terminated with $2 \mathrm{~N} \mathrm{H}_{2} \mathrm{SO}_{4}$. The optical density was measured at $490 \mathrm{~nm}$ using an ELISA microplate reader (Molecular Devices, USA). Total three trials were performed for all samples. End point titers were defined as the maximum dilutions giving an $\mathrm{A}_{490}$ measurement of 0.1 . 
This cutoff value represents the mean optical density plus 2 standard deviations of 10 normal mouse serum samples tested at 1:100 dilutions. Statistical comparison was made by the Mann-whitney $U$ test. To compare the rELISA with commercial NDV diagnosis, an NDV ELISA kit (Easybio, Korea) was tested according to manufacturer's instructions.

\section{RESULTS AND DISCUSSION}

Sub-cloning of pET43-1a: HN was confirmed by RE digestion and sequencing and there was no unwanted substitution on the amino acid sequence of the synthesized HN produced by overlapping PCR. Prokaryotic expression was performed in transformed protein was found in the insoluble fraction as shown in Fig. 2. Maximum expression was observed between 2 and $4 \mathrm{~h}$ and drastically decreased after $4 \mathrm{~h}$. In both soluble and insoluble fractions, highest expression was detected at $4 \mathrm{~h}$ after IPTG induction. Purification of the expressed fusion forms of His-NDV HN was performed by Ni-NTA metal affinity chromatography following manufacturer's instruction. Similar to the findings confirmed in Westernblot prior to purification, the $75 \mathrm{kDa}$ fusion protein was positively selected by the Ni-NTA agarose purification (Fig. 3). Very few proteins were eluted from the first washout fraction but no other protein was detected from the following washing steps. Most of the purified $\mathrm{HN}$ protein was collected from the first and second elution steps. The average yield of purified NDV HN fusion

(a)

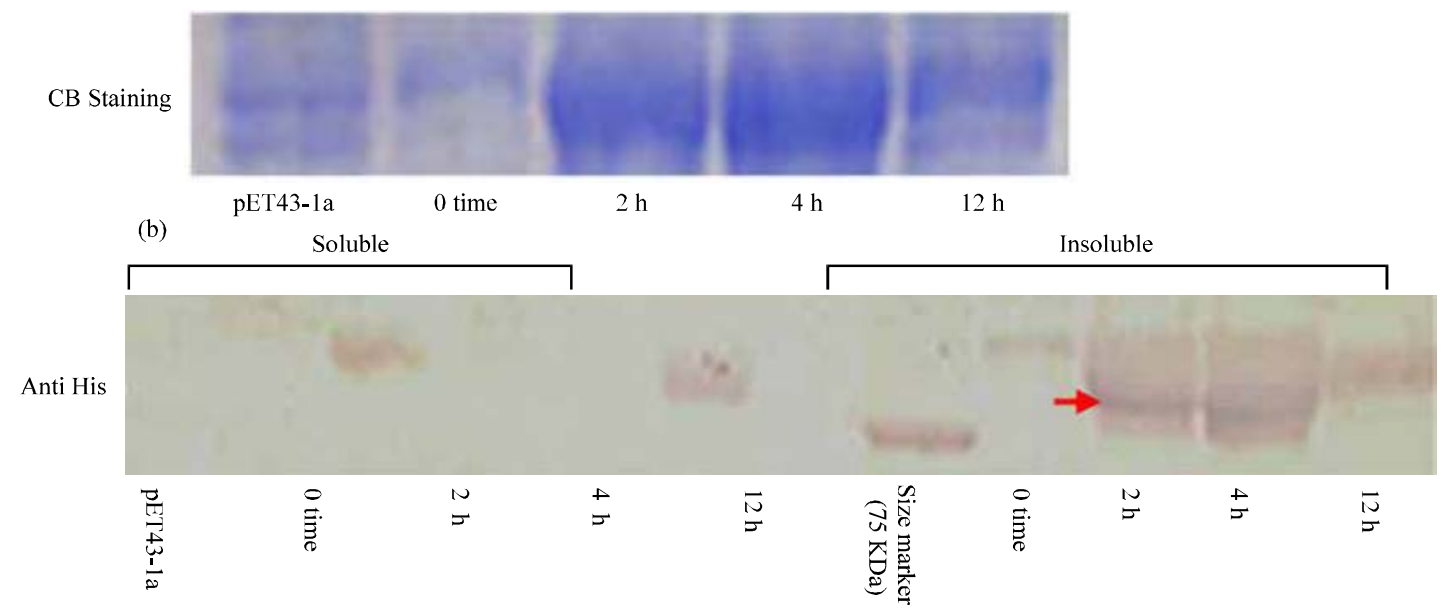

Fig. 2: Confirmation of the NDV HN protein. The expression and purification of NDV HN protein in $E$. coli. a): DE3(BL21) cell was transformed with the verified pET43-1a: NDV HN plasmid and induction was carried out at $30^{\circ} \mathrm{C}$. Obviously, the expression of NDV HN protein was increased at $2 \mathrm{~h}$ after IPTG treatment. It was confirmed by Coomassie brilliant blue staining on SDS-PAGE. b): The configuration of NDV HN protein within soluble and insoluble forms was confirmed by Western blotting using anti- $6 \mathrm{x}$ His antibody. The arrow indicates the expected size of the target protein. Both a and b shows the highest expression of the protein at $4 \mathrm{~h}$

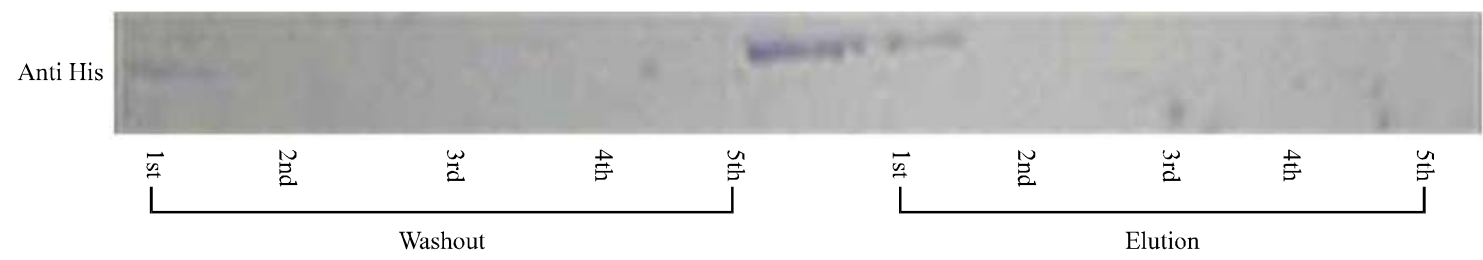

Fig. 3: Confirmation of the purified NDV HN protein. The confirmed clone which expresses the NDV HN fusion protein was cultured in $200 \mathrm{~mL}$ LB broth and purification was performed. The average yield of purified NDV HN fusion protein was approximately $2.6 \mu \mathrm{g}$ from the culture. After 5 times of washing out, the 1 and 2 fraction of elution showed the purified NDV HN protein through Ni-NTA agarose beads column. This was confirmed by Western blotting using anti $6 \times$ His tag antibody 
protein was approximately $2.6 \mu \mathrm{g}$ per $200 \mathrm{~mL}$ culture. To verify whether the expressed protein retained similar antigenic property with native NDV HN protein, it was evaluated with sera from NDV immunized chickens. Total five different sera from different farms that have been vaccinated with different strains of vaccines positively reacted with the purified protein in Western blot. In contrast, those purified $\mathrm{HN}$ protein did not react with negative control serum (Fig. 4). The feasibility of using the expressed NDV HN protein as a coating antigen for rHN-ELISA was evaluated. Comparison of the ELISA results with commercial NDV ELISA kit which used whole NDV as the coating antigen is shown in Fig. 5. Most of the field collected sera showed high $O D$ value in commercial kit while only a few sera showed high $O D$ value in $r H N$-ELISA. While the OD value of the samples detected by the rHN-ELISA was not as high as that of commercial ELISA, the rHN-ELISA offers the possibility of serological differentiation between NDV negative and positive sera. A correlation between the ELISA result and $\mathrm{HI}$ titer was evaluated. As shown in Fig. 5 while most of the field sera showed high $O D$ values with the commercial ELISA kit, this did not translate to high $\mathrm{HI}$ titer. The same pattern was observed with the rHN-ELISA.

The cut-off point for protective $\mathrm{HI}$ titer averaged a 10 in this study. However, $>65 \%$ of samples did not reach that level. In Fig. 5, samples 1 and 2 were negative control and they showed low level of $\mathrm{HI}$ titer in both diagnostic methods was on expected lines while some samples such as 19 and 22, showed high antibody titer to both ELISA and over the cut-off point of $\mathrm{HI}$ titer. It can be inferred that only few samples had sufficient protective antibodies. Other samples like 21, 28, 36 and 37 also, showed high level of $\mathrm{HI}$ titer only in commercial ELISA. These samples might have some correlations against other neutralizing epitopes of NDV apart from $\mathrm{HN}$.

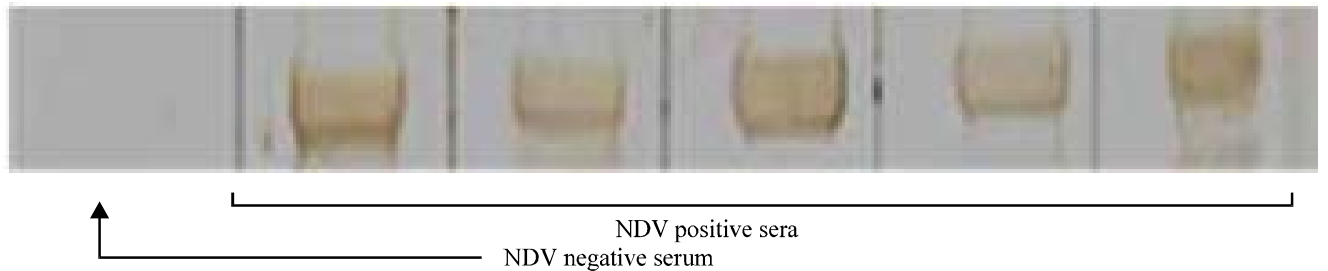

Fig. 4: Confirmation of antigenicity of the purified NDV HN protein. The purified protein was confirmed by Western blotting with the collected field sera which showed positive reaction against NDV. Same volume of the purified NDV HN protein was loaded on each lane and the antigenic interaction was confirmed by using NDV negative (1 st lane) and NDV positive (the other lanes) chicken sera

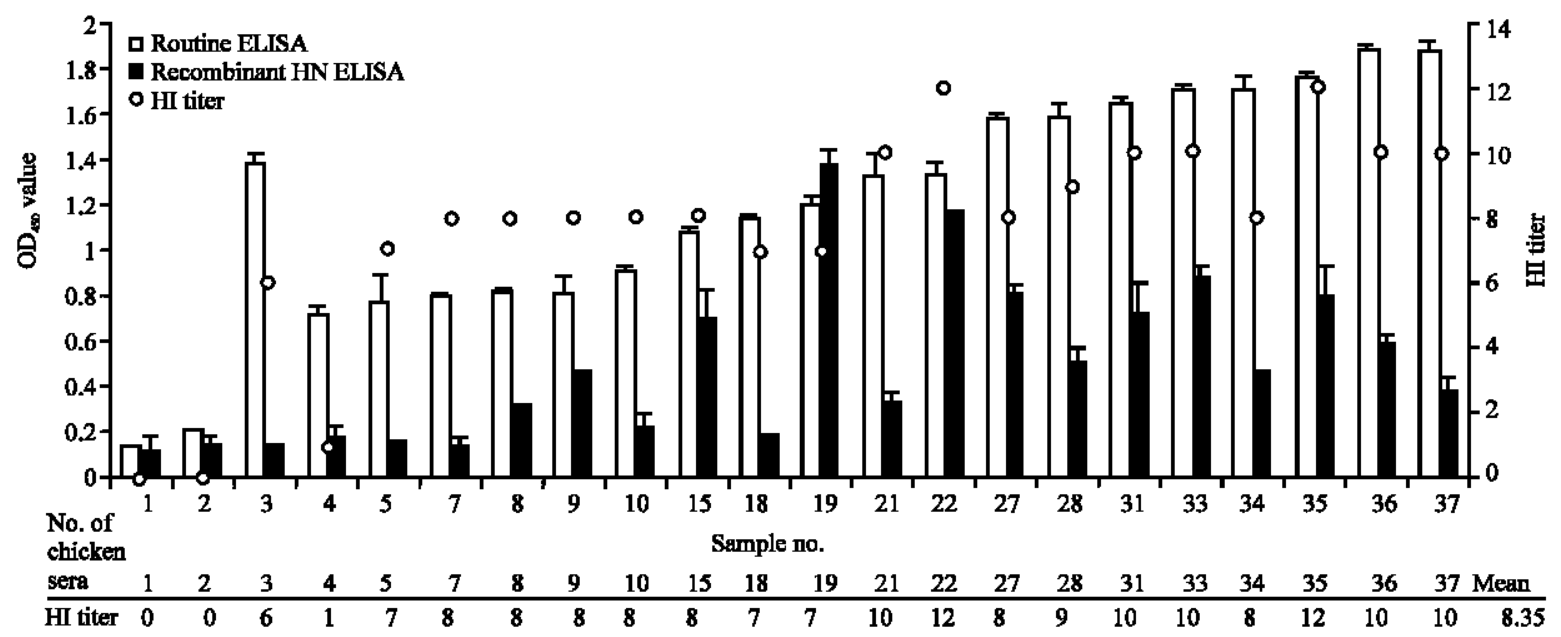

Fig. 5: Comparison result among the commercialized diagnosis, recombinant HN ELISA and HI titer of chicken sera. All the samples of chicken serum were tested by triplicate. The data are presented as means standard deviations. Statistical comparisons between samples were made by the Mann-Whitney $U$ test. The raw data of $H I$ test shows below the figure. Each sample was examined by the commercialized diagnostic method ( $\square$ ) rELISA ( $\square$ ) and HI test (O). The sample number 1 and 2 are NDV negative chicken sera 
Though, sufficient immune responses were elicited against the NDV vaccines these anti-NDV antibodies were not correlated with virus neutralizing activity. Therefore, using whole NDV as a vaccine and as a diagnostic reagent was not efficient in conferring protective immunity nor did it reliably evaluated the efficacy of the vaccines.

Newcastle disease is one of the most important infectious diseases in poultry that results in huge financial losses in poultry farms (Mebatsion et al., 2002). Due to the ineffectiveness of the vaccines and vaccination strategies as well as the unavailability of highly specific and precise diagnostic tools, recurrent outbreaks of the disease are reported globally. Many of the detection methods on NDV such as isolation, ELISA, PCR, HI test and IFA have been reported (Kho et al., 2000; Panda et al., 2004). Among them, ELISA is the most popular and common of the detection methods. This method is used for epidemiologic surveillance and outbreak reports in many countries.

However, the present ELISA systems may not provide a reliable evaluation on the efficacy of vaccination since, the system detects antibodies against a wide a range of viral proteins. In reality, $\mathrm{HN}$ and $\mathrm{F}$ glycoproteins play important role in the antigenicity and immunogenicity of the virus (Morrison, 2003; Orvell et al., 1997). Higher titres recorded by traditional ELISA or $\mathrm{HI}$ tests may give exaggerated titres due to responses against non $\mathrm{HN} / \mathrm{F}$ proteins such as NP.

This may, therefore be attributed for repeated outbreaks even after recording sufficient antibody titres. Thus to properly evaluate the efficacy of vaccines, the present study focused on the $\mathrm{HN}$ protein containing known neutralizing epitopes of NDV.

Most diagnostic laboratories are using whole NDV as the ELISA coating antigen for detection (Miers et al., 1983; Snyder et al., 1983; Wilson et al., 1984; Rivetz et al., 1985). Because of lack of proper cell lines for NDV culture, SPF eggs are often used for NDV culture and coating antigen preparation. Another method, serum neutralizing test (SN test) which detects neutralizing antibodies is also difficult to perform because of the unavailability of cell lines for NDV propagation. Therefore, simpler and easier methods for antigen preparation are required. A decade ago, Makkay et al. (1999) succeeded in the expression of recombinant $\mathrm{F}$ and $\mathrm{HN}$ proteins using fowlpox virus. However, it still had some problems in its cost and yield. In contrast the present study, the $\mathrm{HN}$ protein used as the coating antigen for the rHN-ELISA was produced using a prokaryotic expression system that is rapid, easy to modify and cost effective. While there are certain drawbacks in the system like the absence of post- translational modifications such as glycosylation and phospholyration, results of the experiment showed that the expressed $H N$ protein from $E$. coli were antigenically similar to native $\mathrm{HN}$ protein and was sufficient for detection. NDV HN protein expression in E. coli has not been reported, yet.

Therefore to induce high rate of $\mathrm{HN}$ expression, substitution of the HN nucleotides by optimal codon usage within no variation of amino acid sequences was performed (Henaut and Danchin, 1996). The aim of vaccination is to induce the production of sufficient protective neutralizing antibodies. It has been reported that neutralizing antibodies against NDV are induced by $\mathrm{HN}$ and $\mathrm{F}$ proteins present on the NDV envelope (Chambers et al., 1988; Mebatsion et al., 2002). Even if antibody titer in ELISA is high do not provide expected protection. Although, HI test is not an obvious method for detection of neutralizing antibodies, it is the only available method to evaluate the kind of blocking antibodies against NDV (Daniel, 1987). But the HI test is also needed for sufficient validation even though they are not expectedly correlated with ELISA results.

Because of the high maintenance cost of NDVsusceptible cell lines, a novel effective diagnostic method using $\mathrm{rHN}$ protein as a coating agent was developed. This system is more economical, easy to handle and produced comparatively accurate results. Non-correlated titres of $\mathrm{HI}$ and OD values of ELISA were mainly attributed to the neutralizing antibodies directed against other glyco proteins which may be a reason for outbreak of the disease in high titre flocks.

While comparing the rHN-ELISA with that of $\mathrm{HI}$ and commercial ELISA, variation of multiple epitope-directed neutralizing antibodies (which were collectively measured in $\mathrm{HI}$ titres) were measured in commercial ELISA, yielding higher results. Large production of non- $\mathrm{HN}$ or $\mathrm{F}$ antibodies against NDV may also be caused by the characteristics of Paramyxoviruses transcription. Because of the genome organization of NDV, mRNA for nucleocapsid protein is produced most abundantly, resulting in large amounts of NP protein. The NDV NP protein is the predominant protein in among all those NDV structural proteins and induces high amount antibody as well which is not detected by rHN-ELISA.

The rHN-ELISA only detects antibodies that are specific to the $\mathrm{HN}$ proteins which may explain the discrepancy in the results when compared to the commercial NDV ELISA kit. On the other hand, the high level of antibody titer obtained from the commercial ELISA kit may not reflect the immunoprotective response against NDV since, most of the antibodies might be directed against non $\mathrm{HN}$ or $\mathrm{F}$. Therefore, evaluation of 
neutralizing antibodies directed primarily against $\mathrm{HN}$ proteins would give a more realistic evaluation of the immune status after delivery of a particular NDV vaccine.

\section{CONCLUSION}

The purpose of preventive vaccination should be to produce sufficient neutralizing antibodies. Nevertheless, most of induced antibodies from present vaccination do not induce enough neutralizing activities. And also, even after continuous efforts on improving NDV vaccination strategies, the reason why outbreak reports every year would be explained by these results. The novel rHNELISA method developed in this study would evaluate the neutralizing antibodies which are produced against $\mathrm{HN}$ proteins which are responsible for antigenicity of the virus unlike commercially available ELSA kit and $H I$ methods. Therefore, evaluating antibodies produced against other proteins of the virus which are seldom related to viral pathogenicity of field viruses bears no significant importance to disease prevention. Further improvement, standardization and validation of the rHNELISA method may expect more specific evaluation of immunity against NDV and development of specifically directed vaccines.

\section{ACKNOWLEDGEMENTS}

This research is supported by Agricultural R\&D Promotion Center (Grant No. 203109033SB010) and partially supported by small and medium business administration.

\section{REFERENCES}

Ahmad-Raus, R., A.M. Ali, W.S. Tan, H.M. Salleh, M. Eshaghi and K. Yusoff, 2009. Localization of the antigenic sites of newcastle disease virus nucleocapsid using a panel of monoclonal antibodies. Res. Vet. Sci., 86: 174-182.

Chambers, P., M. Nesbit, K. Yusoff, N.S. Millar, A.C. Samson and P.T. Emmerson, 1988. Location of a neutralizing epitope for the haemagglutininneuraminidase glycoprotein of Newcastle disease virus. J. Gen. Virol., 69: 2115-2122.

Chimeno, Z.S., E. Gomez, E. Carrillo and A. Berinstein, 2008. Locally produced mucosal IgG in chickens immunized with conventional vaccines for Newcastle disease virus. Braz. J. Med. Biol. Res., 41: 318-323.

Daniel, J.K., 1987. Virus isolation from oroparyngeal swabs in attempts to detect persistent Newcastle disease virus infection in chicken. Avian Dis., 31: 293-301.
Han, G.Z., C.Q. He, N.Z. Ding and L.Y. Ma, 2008. Identification of a natural multi-recombinant of Newcastle disease virus. Virology, 371: 54-60.

Henaut, A. and A. Danchin, 1996. Escherichia coli and Salmonella: Cellular and Molecular Biology. 2nd Edn., Vol. 2, ASM Press, Washington, pp: 2047-2066.

Huang, Z., A. Panda, S. Elankumaran, D. Govindarajan, D.D. Rockemann and S.K. Samal, 2004. The hemagglutinin-neuraminidase protein of newcastle disease virus determines tropism and virulence. J. Virol., 78: 4176-4184.

Kho, C.L., M.L. Mohd-Azmi, S.S. Arshad and K. Yusoff, 2000. Performance of an RT-nested PCR ELISA for detection of Newcastle disease virus. J. Virol. Methods, 86: 71-83.

Kim, S.T., I.H. Park, S.K. Kim, Y.H. Kim, K.H. Cho and S.J. Kwon, 2001. Studies on the immunization against field strain after live Newcastle disease virus vaccination. Korean J. Vet. Service, 24: 147-159.

Laliberte, J.P., L.W. McGinnes and T.G. Morrison, 2007. Incorporation of functional HN-F glycoproteincontaining complexes into newcastle disease virus is dependent on cholesterol and membrane lipid raft integrity. J. Virol., 81: 10636-10648.

Lamb, R.A. and G.D. Parks, 2007. Paramyxoviridae: The Viruses and Their Replication. In: Fields Virology, Knipe, D.M. and P.M. Howley (Eds.). 5th Edn., Kluwer Publisher, Netherlands, pp: 1449-1496.

Makkay, A.M., P.J. Krell and E. Nagy, 1999. Antibody detection-based differential ELISA for NDV-infected or vaccinated chickens versus NDV $\mathrm{HN}$-subunit vaccinated chickens. Vet. Microbiol., 66: 209-222.

Mayo, M.A., 2002. A summary of taxonomic changes recently approved by ICTV. Arch. Virol., 147: 1655-1663.

Mebatsion, T., M.J.M. Koolen, L.T.C. de Vaan, N. de Haas and M. Braber et al., 2002. Newcastle disease virus (NDV) marker vaccine: An immunodominant epitope on the nucleoprotein gene of NDV can be deleted or replaced by a foreign epitope. J. Virol., 76: 10138-10146.

Miers, L.A., R.A. Bankowski and Y.C. Zee, 1983. Optimizing the enzyme-linked immunosorbent assay for evaluating the immunity of chickens to Newcastle disease. Avian Dis., 27: 1112-1125.

Morrison, T.G., 2003. Structure and function of a paramyxovirus fusion protein. Biochim. Biophys. Acta, 1614: 73-84. 
Orvell, C., A.R. Alsheikhly, M. Kalantari and B. Johansson, 1997. Characterization of genotypespecific epitopes of the $\mathrm{HN}$ protein of mumps virus. J. Gen. Virol., 78: 3187-3193.

Panda, A., Z. Huang, S. Elankumaran, D.D. Rockemann and S.K. Samal, 2004. Role of fusion protein cleavage site in the virulence of Newcastle disease virus. Microb. Pathogenesis, 36: 1-10.

Perozo, F., R. Merino, C.L. Afonso, P. Villegas and N. Calderon, 2008. Biological and phylogenetic characterization of virulent newcastle disease virus circulating in Mexico. Avian Dis., 52: 472-479.

Rivetz, B., Y. Weissman, M. Ritterband, F. Fish and M. Herzberg, 1985. Evaluation of a novel rapid kit for the visual detection of Newcastle disease virus antibodies. Avian Dis., 29: 929-942.
Snyder, D.B., W.W. Marquardt, E.T. Mallinson and E. Russek, 1983. Rapid serological profiling by enzymelinked immunosorbent assay. I. Measurement of antibody activity titer against Newcastle disease virus in a single serum dilution. Avian Dis., 27: 161-170.

Tabidi, M.H., A. Makkawi, E. Mahasin and A.S. Ali, 2004. Comparative evaluation of haemagglutination inhibition test and enzyme-linked immunosorbent assay for detection of antibodies against newcastle disease vaccine in broiler chicks. Int. J. Poult. Sci., 3: $668-670$.

Wilson, R.A., C.Jr. Perrotta, B. Frey and R.J. Eckroade, 1984. An enzyme-linked immunosorbent assay that measures protective antibody levels to Newcastle disease virus in chickens. Avian Dis., 28: 1079-1085. 